\title{
Pasteurization: A reliable method for preservation of nutrient in seawater samples for inter-laboratory and field applications
}

\author{
Anne Daniel*, Roger Kérouel, Alain Aminot
}

IFREMER, Dyneco-Pelagos, BP 70, 29280 Plouzané, France

*: Corresponding author : Anne Daniel, Tel.: + 33298224343 ; email address : Anne.Daniel@ifremer.fr

\begin{abstract}
:
Following previous work, the production of reference material for nutrients in seawater, using pasteurization as a preservation method, was carried out seven times between 2006 and 2010 in the framework of inter-laboratory exercises. The preparation of samples from natural seawater allowed to become depleted in nutrients then spiked, bottled and pasteurized, is described. Five main nutrients are involved in this study: ammonium, nitrite, nitrate, phosphate and silicate. Bottles are in glass for the ammonium samples and in plastic for the other nutrients. Pasteurization was performed at $80 \pm 3{ }^{\circ} \mathrm{C}$ for $2 \mathrm{~h}$. Samples were controlled for homogeneity and stability at $3-5$ month interval, before and after the period allocated for each exercise and a third time between 8 to 40 months storage. Homogeneity, not altered by sample aging, remains within a few nanomoles per litre for nitrite $(<1.4 \mu \mathrm{mol} / \mathrm{L})$ and phosphate $(<3 \mu \mathrm{mol} / \mathrm{L})$ and within a few tens of nanomoles per litre for ammonium $(<4.5 \mu \mathrm{mol} / \mathrm{L})$, nitrate $(<35 \mu \mathrm{mol} / \mathrm{L})$ and silicate $(<30 \mu \mathrm{mol} / \mathrm{L})$. Except for ammonium, stability data are close to homogeneity data at the low level and within $0.3-0.5 \%$ at the high level. Ammonium shows a slight drift due to atmospheric contamination through the plastic cap, in the order of $0.1 \mu \mathrm{mol} / \mathrm{L}$ per year, which allows nevertheless an acceptable performance over an 1-2 month analytical delay.
\end{abstract}

Except for ammonium, pasteurization does not produce detectable concentration changes, thus it can be applied to field samples for long term storage at ambient temperature.

\section{Highlights}

Pasteurization to prepare nutrients reference material and to preserve field samples. Homogeneity and stability studies better than a few ten nanomoles. Production of samples for interlaboratory exercises as a robust method validation.

Keywords: Pasteurization ; Nutrients ; Seawater ; Inter-laboratory exercises 


\section{Introduction}

Quality assurance, which has become a major laboratory activity for guaranteeing satisfactory analytical performance, relies primarily on stable reference materials. Because of their high bio-activity, macro-nutrients (N, P and Si compounds) are generally unstable in untreated natural seawater samples. This has in the past made it difficult to organize inter-laboratory exercises some decades ago. In the sixties and seventies, the first three ICES (International Council for the Exploration of the Sea) exercises involving nutrients were conducted either on-board ships with freshly collected water or using artificial standards solutions (see Annex 1 in Aminot and Kirkwood, 1995). After that, no exercise has taken place until 1989. In this fourth ICES exercice (Aminot and Kérouel, 1991), two stable samples (natural deep-sea water or autoclaved seawater) were available on a large scale for nitrate and phosphate (Kirkwood et al., 1991). Autoclaved seawater became the only material distributed for the fifth exercise in 1993 (Aminot and Kirkwood, 1995) while it was assessed for long term stability of nitrate, phosphate, nitrite and ammonium (Aminot and Kérouel, 1995). Subsequently, autoclaving was applied to produce nutrient reference material for the European project Quasimeme (Aminot and Kérouel, 1997a), then developed on a wider scale by the MRI (Japanese Meteorological Research Institute) who organized international intercomparison exercises based on samples prepared using this process (Aoyama et al., 2007, 2008).

However, in spite of its efficiency for the stabilization of seawater nutrient samples, the drawback of autoclaving is the high temperature required for the treatment $\left(120^{\circ} \mathrm{C}\right)$. First, previous data (Aminot and Kérouel, 1991; 1995) showed that phosphate and ammonium concentrations change slightly: both nutrients from the production of measurable concentrations from hydrolysis of dissolved organic matter, phosphate from the precipitation of calcium phosphates at high phosphate levels (e.g. deep seawater). Although such side processes are minor problems for reference material, whose stability is far more important than their initial concentration, they can limit application of the material if they alter variability and if very low concentrations of phosphate and ammonium have to be obtained. Secondly, for pasteurization, either plastic or glass bottles can be used, depending on whether or not silicate analysis is required. However, while glass bottles can be directly autoclaved, using adequate closing, thin plastic bottles (polypropylene or high density polyethylene) imply a two-step process involving sterilising a bulk water followed by filling the bottles in a sterile room (Ota et al., 2010).

From knowledge gained in previous heat treatment studies (Aminot and Kérouel, 1997b) pasteurization was proposed for the preservation of nitrate and nitrite in seawater samples (Aminot and Kérouel, 1998). Then, the field of pasteurization was enlarged to the production of reference material for several nutrient inter-laboratory exercises (ILE) from 2006 to 2010. The present paper describes this application over five years (14 samples with different concentrations, prepared independently for each round) as a robust validation of the method. Additionally, the five nutrients of importance (ammonium, nitrite, nitrate, phosphate, silicate) were included in these experiments. 


\section{Material and method}

\subsection{Overview}

The reference material was prepared for the ILE organized for the French oceanographic community in the framework of the Ifremer quality assurance programme. Seven ILE, each with two lots of samples, were proposed between 2006 and 2010, each ILE involving about 25 independent laboratories. Samples were prepared from low nutrient seawater (LNSW) spiked or not with nutrient salts to obtain low level and high level samples. For operational reasons, the samples were prepared during two successive days, one for each concentration level, and each level required two separate bulks of water, one for silicate and phosphate and the other for the three nitrogenous nutrients. The samples were stored in a special clean room (no chemicals stored) before being distributed to the participating laboratories or analysed on site.

The nutrient concentrations were checked by the organizing laboratory (Ifremer Brest) on several occasions: 1) before pasteurization of the samples; 2) just after pasteurization (homogeneity test); 3) 3-4 months later (initial stability test); 4) after longer storage periods (8 to 40 months, depending on the date of the ILE preparation; final stability test) for the four ILE organized between 2007 and 2009. Steps 2 and 3 were required by the ILE validation process, while steps 1 and 4 were additional tests in order to check more precisely performance of the pasteurisation process.

Regarding the ILE, the samples were sent to the laboratories within a few weeks after their preparation. Participating laboratories had to return their results within two months after sample receipt.

\subsection{Preparation and conditioning of seawater samples to be pasteurised}

LNSW is the same as the matrix used for nutrient calibration (Aminot et al., 2009). Seawater was sampled near the entrance of the Bay of Brest, each year in September at spring tide and at high tide in order to collect a high salinity marine water with low nutrient concentrations. This water was screened at $50 \mu \mathrm{m}$ to remove zooplankton, and then stored in daylight in a non opaque polyethylene carboy for at least 5-6 months in the laboratory in order for phytoplankton to deplete most nutrients present to almost undetectable levels. The water can then be used for up to 2 years, as long as $\mathrm{pH}<8.5$.

For the preparation of each ILE, about $50 \mathrm{~L}$ of the depleted water were filtered on-line through a GF/F Whatman glass-fibre membrane $(\sim 0.7 \mu \mathrm{m}$ pore size; diam. $150 \mathrm{~mm})$ fitted in a teflon Millipore filter-holder connected to a transfer pump (very low vacuum generated). The glass fibre membrane was selected for its high filtration rate; its slight silicate contribution is unimportant in the present exercises. The water was collected in a polyethylene carboy and analysed for salinity, nutrients and $\mathrm{pH}$. Since phosphate precipitation was previously observed during autoclaving (Aminot and Kérouel, 1991), this potential problem was overcome by lowering the $\mathrm{pH}$ to $7.4 \pm 0.1$ in the bulk designed for phosphate determination. A titration was performed to determine the amount of acid needed. After pasteurization, sample $\mathrm{pH}$, which increases slightly, lays in the range 7.78.2 for all samples. Two sub-volumes were extracted from the main bulk and placed in two carboys (carefully rinsed with LNSW) : the first was devoted to the phosphate and silicate sample preparation (about $8 \mathrm{~L}$ ) and the second to the nitrogenous nutrients samples preparation (about $15 \mathrm{~L}$ ). Carboys and water masses were weighed (using a $61 \mathrm{~kg} \pm 1 \mathrm{~g}$ Sartorius F61S balance) and the seawater volume was computed from the salinity-density 
relationship. Then the amounts of acid and nutrient standards need to be precisely determined to obtain the expected $\mathrm{pH}$ and concentrations. For the preparation of samples of lower salinity, deionised Milli-Q ultrapure water was poured to the carboys then seawater, each water in the amount which has been computed to obtain the expected salinity. Once the carboy contents have been thoroughly mixed, samples were withdrawn. For a given nutrient level, a set of 3 bottles were filled for each participating laboratory: two high density polyethylene bottles (HDPE; $125 \mathrm{~mL}$, Nalgene 2002-0004), one for silicate and phosphate and the other for nitrite and nitrate determinations, and one ordinary glass bottle with a leakproof linerless polypropylene screwcap for ammonium determination ( $250 \mathrm{~mL}$ until ILE 3, then $100 \mathrm{~mL}$ ). To provide separated bottles for the various nutrients was mandatory for the laboratories using manual analytical methods. The bottles need to be capped tightly, first by hand and then gently with pliers before the pasteurization process.

\subsection{Pasteurisation process}

The samples were pasteurized at $80 \pm 3{ }^{\circ} \mathrm{C}$ for two hours. This temperature was determinated by previous experiments (Aminot and Kérouel, 1997b). Two ovens (108 L, no fan, Memmert) were required to pasteurize all the samples of each concentration at the same time : one oven was devoted to ammonium samples in glass bottles, the other to all the other samples. Temperature of water samples during treatment was measured by probes dipped in two witness bottles placed among the samples, on the lowest and the highest tray of each oven. The oven temperature was initially set at about $100-110{ }^{\circ} \mathrm{C}$, then when the sample temperature approaches the $80^{\circ} \mathrm{C}$ setting, the temperature was lowered to maintain the samples at the correct temperature of $80^{\circ} \mathrm{C}$.

At the end of the heating period the bottles were removed from the ovens using gloves, the loosened caps were firmly re-tightened and the samples were left on a benchtop in a clean room to cool to room temperature (according to previous in-house data relating to autoclaving, we observed that cooling too fast or too slow may induce some phosphate loss in rich samples). Then, each bottle was placed in a plastic bag which was heatsealed and the samples were stored at room temperature in a dark and clean place, until needed.

\subsection{Analytical methods}

Nutrient concentrations were measured using a Seal Autoanalyzer AA3 following methods detailed in Aminot et al. (2009) with particular attention to method calibration. Thus, the nitrite primary standard solution was renewed at each ILE and the other nutrients solutions yearly (Aminot and Kérouel, 1996). These were prepared from the following salts of certified purity: $\left(\mathrm{NH}_{4}\right)_{2} \mathrm{SO}_{4}$ (Fluka 09980, $99.70 \%$ ), $\mathrm{NaNO}_{2}$ (Aldrich 431605, $99.995 \%$ ), $\mathrm{KNO}_{3}$ (Merck 1.05065, $99.995 \%$ ), $\mathrm{KH}_{2} \mathrm{PO}_{4}$ (Fluka 60216, $99.996 \%$ ), Na $\mathrm{NiF}_{6}$ (Fluka 71596, $99.8 \%$ ). All the working standards were prepared by dilution in LNSW. New and old standards were cross-controlled and validated against Merck CertiPUR (NIST controlled) $1 \mathrm{~g} / \mathrm{L}$ standard solutions (ref.: $\mathrm{NH}_{4} \mathrm{Cl}$ 119812, $\mathrm{NaNO}_{2}$ 119899, $\mathrm{NaNO}_{3} 119811$, $\mathrm{KH}_{2} \mathrm{PO}_{4}$ 119898, $\left.\left(\mathrm{NH}_{4}\right)_{2} \mathrm{SiF}_{6} 112310\right)$. The automatic pipettes were also systematically checked. Furthermore, the laboratory has been a regular participant in the international Aoyama's ILE since 2003. Analytical precision was optimised by measuring the low and high sample concentration levels in two separated runs with specific four points calibration ranges and colorimeter settings corresponding to these levels. Each sample concentration is the mean of 10 determinations from 5 randomly selected samples analysed twice in random order, separated by two blanks of ultrapure water. The duplicate determinations 
enable the assessment of analytical repeatability (according to : $s=\left(\Sigma\left(x_{1}-x_{2}\right)^{2} / 2 n\right)^{0.5}$ ) throughout the 5-year period which is summarized in table 1.

Salinity was measured using a Guildline Portasal salinometer and $\mathrm{pH}$ measured on the NIST scale with commercial buffers, using a WTW pH 340 pHmeter equipped with a WTW $\mathrm{pH} /$ temperature combined electrode.

At any stage of the sample preparation and analysis, powder-free latex or nitrile gloves were worn to avoid risks of contamination.

\section{Results}

\subsection{Characteristics of the LNSW and the samples}

Before starting any sample preparation, the principal characteristics of the LNSW were checked (table 2). The salinity of these waters was $35 \pm 0.3$ and their $\mathrm{pH}$ between 8 and 8.2. Nutrients concentrations, which were generally at measurable concentrations when sampling, have decreased below or close to the detection limit after storage of a few months, except for silicate.

The concentration ranges of the samples prepared by spiking the LNSW were 0.05-4.5 $\mu \mathrm{mol} / \mathrm{L}$ for ammonium, 0.1-1.4 $\mu \mathrm{mol} / \mathrm{L}$ for nitrite, $1.0-35 \mu \mathrm{mol} / \mathrm{L}$ for nitrate, $0.1-2.9 \mu \mathrm{mol} / \mathrm{L}$ for phosphate and 1.1-29 $\mu \mathrm{mol} / \mathrm{L}$ for silicate (table 2).

\subsection{Effect of pasteurization on nutrient concentrations}

The effect of pasteurization on nutrient concentrations was determined by comparing concentrations measured before and after pasteurization. These are summarized in table 3 as means and standard deviations of data from the seven ILE.

Except for ammonium, the effect of pasteurization on the nutrient concentrations was not significantly different from zero at the analytical precision. For nitrite and nitrate no effect was expected since autoclaving has been shown to not compromise the samples (Aminot and Kérouel, 1991; 1995). Similarly for silicate, Ota's (2010) showed that autoclaving almost insignificantly altered the concentrations, thus pasteurization should normally not induce any change. For phosphate and ammonium it was expected that reducing the heating temperature compared with autoclaving should have positive effects. While 0.01 to $0.05 \mu \mathrm{mol} / \mathrm{L}$ of phosphate were produced in LNSW by autoclaving (Aminot and Kérouel, $1995 ; 1997 \mathrm{~b})$, no detectable change in concentration $(0.001 \mu \mathrm{mol} / \mathrm{L})$ was produced by pasteurization. Additionally, high concentration levels seem unaffected by the treatment within $0.4 \pm 0.5 \%(<0.01 \mu \mathrm{mol} / \mathrm{L}$; comparable with the long term precision), while a small decrease or a lesser increase than corresponding unspiked LNSW (0.01-0.05 $\mu \mathrm{mol} / \mathrm{L})$ was induced by autoclaving (Aminot and Kérouel, 1995). A recent experiment at the natural $\mathrm{pH}$ of seawater ( 8.25 vs 7.4 for the ILE) confirmed these data, i.e. that pasteurisation did not induce a phosphate decrease at a level of $3 \mu \mathrm{mol} / \mathrm{L}$ in contrast with autoclaving. For ammonium, the production attributed to hydrolysis of dissolved organic nitrogen (DON) is reduced from 0.1-0.3 $\mu \mathrm{mol} / \mathrm{L}$ under autoclaving (Aminot and Kérouel, 1995) to an average of $0.07 \mu \mathrm{mol} / \mathrm{L}(0.05-0.12)$ by pasteurization. This ammonium produced by the matrix is negatively correlated to the $\mathrm{pH}$ of the LNSW although the $\mathrm{pH}$ itself has no marked effect in 
the range 7-8 (Aminot and Kérouel, 1991). It is thus postulated that the differences result from the nature and amount of LNSW DON, which depends on the aging process like the $\mathrm{pH}$ itself (which is just a marker).

\subsection{Homogeneity of the nutrient concentrations}

Homogeneity was assessed from the analysis of groups of five samples randomly taken from the lots prepared for each ILE. Homogeneity is characterized by the inter-sample variability. However, the measures include two components : the "true" inter-sample variability of concentration and the analytical repeatability. Since these two components are independent, additivity of their variances was assumed. Therefore, "true" inter-sample homogeneity $\left(\mathrm{s}_{\text {sample }}\right)$ was computed from the difference between total inter-sample variance obtained from the determination and analytical variance computed from duplicate determinations, according to:

$$
\mathrm{S}_{\text {sample }}=\left(\mathrm{S}^{2} \text { total }-\mathrm{S}^{2} \text { analysis }\right)^{0.5}
$$

However, except for ammonium, "true" inter-sample variability was so small that it was generally within uncertainty of estimated variances and cannot be computed in about $50 \%$ of samples. Consequently, only the largest value of the seven ILE variance has been retained for each period of control (table 4), which inevitably provides an overestimation of inter-sample variability.

Data show that a high level of homogeneity was preserved up to 40 months with only minor differences from one period to the other. These differences may not be significant with regard to standard deviation uncertainty. Only phosphate seems to exhibit a slight decrease in homogeneity during the first months of storage (but not later) with a standard deviation increasing from 0.001 to $0.006-0.009 \mu \mathrm{mol} / \mathrm{L}$. Homogeneity of the samples at the high concentration level was better than $0.1-0.2 \%$ for nitrate and silicate and $\sim 0.5 \%$ for ammonium, nitrite and phosphate.

During one preparation, some samples placed in HDPE bottles were heated at a temperature slightly higher than $90^{\circ} \mathrm{C}$. While neither concentrations nor homogeneity were altered for nitrate, phosphate and silicate, nitrite concentrations increased by 0.01-0.02 $\mu \mathrm{mol} / \mathrm{L}$ and homogeneity slightly deteriorated ( $\left.s_{\text {sample }}=0.005-0.009 \mu \mathrm{mol} / \mathrm{L}\right)$. This phenomenon was attributed to atmospheric contamination due to a leak at the stoppers arising from HDPE softening combined with higher internal pressure, which shows that the heating process must be rigorously controlled.

\subsection{Stability of the nutrient concentrations}

The stability controls were performed with the extra ILE bottles stored in clean, stable conditions. Stability was assessed using the Spearman correlation test owing to few data with non-normal distribution (table 5 and figure 1). At a confidence level of $95 \%$, only ammonium shows a significant (positive) drift as expected from previous knowledge about storage of autoclaved samples (Aminot and Kérouel, 1995). The other nutrients were stable over the 40-month storage period. Since concentrations of each nutrient vary from one ILE to another, the degree of stability was expressed by the standard deviation of the differences between the first measurement of a sample (homogeneity test) and subsequent measurements (initial and final stability tests). Separately at the low and high level, all the differences from the seven ILE were pooled, thus representing the fluctuations of a fictive concentration equal to zero for all nutrients. These stability data are shown in table 5 . The variability of concentrations obviously includes the long term within laboratory reproducibility, which provides excess values of the true sample stability. These data show that stability of nitrite and phosphate was within a few nanomoles per litre at 
the low level and $\pm 0.4-0.5 \%$ at the high level. For nitrate and silicate it was lower than \pm $0.05 \mu \mathrm{mol} / \mathrm{L}$ at the low level and below $\pm 0.4 \%$ at the high level. Ammonium, despite its drift, remains within $\pm 0.05 \mu \mathrm{mol} / \mathrm{L}$ over 40 months, i.e. no more than $\pm 1.5 \%$ at the high level, which can be considered as a satisfactory result for testing performance of laboratories for that nutrient.

\subsection{Inter-laboratory exercise results}

All the participating laboratories did not measure all of the five nutrients : the number of samples measured varies from 19 to 27 depending of the ILE and of the nutrient. An overall view of the seven ILE (14 lots) is illustrated in figure 2 by the relationship between robust means with standard deviations (ISO 13528:2005) of participant data versus ours. Our data merge the 20 homogeneity/stability controls performed on each sample lot before and after an exercise in order to include any potential variation during the exercise. The allocated ranges for total errors in the European quality assurance Programme Quasimeme (Quasimeme, 2010) are shown in figure 2. It appears that robust standard deviations of the group of laboratories for nutrients are consistent with Quasimeme specifications, except for ammonium.

None of the intercept is significant at the confidence level $(C L)$ of $95 \%$, as well as the slopes for nitrite, nitrate and phosphate which do not significantly differ from the unity. The slopes for ammonium and silicate are significantly lower than the unity: respectively 0.955 (95\% CL range: 0.926-0.985) and 0.977 (95\% CL range: 0.965-0.989). To explain these results, it was suspected that the slope of the calibration may have been too steep, resulting in an underestimation of the concentration observed for both nutrients.

For ammonium, this could have been due to the difficulty to handle samples at micromolar levels without a risk of contamination. Hence, to minimise this risk, detailed instructions were given to the participants and the sample volume was determined so that transfering the sample was not necessary in most cases. It is assumed that participants have correctly applied the instructions regarding the samples, but that their standards prepared in volumetric flasks may have been more or less contaminated which has produced lower sample values in average. The relatively high standard deviations for this nutrient show how ammonium is difficult to measure accurately. Robust standard deviation of participant data mostly remain within the range of plus or minus the total error allocated by the Quasimeme programme.

For silicate, it is known that the analytical sensitivity is reduced by a salt effect in seawater and that a correction should be made accordingly when calibration is performed in fresh water (Bakker et al., 2010). Since some of the participating laboratories measure usually fresh water, correction for the salt effect has been omitted in many measurements. The magnitude of the deviation from unity is consistent with this hypothesis.

\section{Discussion and conclusion}

Laboratory intercomparison exercises require homogeneous samples, stable over relatively long periods, that require simple storage conditions and no interfering substance added for their preservation. Reviews of the preservation methods (Aminot and Kérouel, 1995) classically recommended in textbooks (freezing, chemical preservatives) conclude that none of them offers the advantages of heat treatments for reference material preparation. 
With the increasing demand of reference materials, their preparation should become easier and less expensive, as well as easy to mail, store and use. As far as possible, laboratories should have an easy access to the preparation of stable internal laboratory reference material. A reference material is preferably based on natural water, and its main characteristics are a low variability and a satisfactory stability over the period of time assigned for its use, even though minor changes of the original concentrations occur during the treatment without alteration of homogeneity. This is not the case of gamma-ray irradiation, for instance, which has been used to produced a so-called "reference material" but initiates random oxido-reductive reactions, and thus must be rejected (Clancy and Willie, 2004). In contrast, autoclaving has been proved to be a reliable method which is now internationally applied by Aoyama and co-workers. Unfortunately, it is not directly applicable to plastic sample bottles which require a constraining two step operation in sterile conditions. On the opposite, pasteurization which uses normal ovens, present in most laboratories, allows direct, one-step treatment of samples in plastic bottle.

In this work, we showed that pasteurization, within the given conditions, enables the preparation and storage of reference material at ambient temperature, for up to several years, for the determination of the major nutrients in seawater (except ammonium). These samples keep high levels of homogeneity and stability over periods far exceeding the normal delay usually allocated to the participants of inter-laboratory exercises. Roughly, homogeneity remains within a few nanomoles per litre for nitrite and phosphate and within a few tens of nanomoles per litre for the other nutrients. Except ammonium, standard deviations for stability (up to 40 months) are like those of homogeneity at the low level and within 0.3-0.5 \% at the high level. According to the norm ISO 13528:2005 stating that homogeneity and stability should be about three times less than the participant allocated performance, these reference material would meet the requirements stated in the GOSHIP Manual (2010) and issued from the World Ocean Circulation Experiment (WOCE) Hydrographic Programme (WHP) which recommended an accuracy of 1\%, 1-2 \%, 1-3 \% for nitrate, phosphate and silicate, respectively (Joyce and Corry, 1994).

The seven ILE performed over 5 years give a robust validation of the nutrient preservation method. While pasteurization had been previously validated for field samples only for nitrate and nitrite (Aminot and Kérouel, 1998), it is now demonstrated that phosphate and silicate can also be preserved by that method without concentration changes due to the treatment. Our recent data show that no loss of phosphate is observed even when the $\mathrm{pH}$ of the seawater is kept in its natural value: this enlarges the use of pasteurisation. Application for field samples is therefore possible also for these two nutrients, which makes simple the storage and transport of control samples collected during deep-sea cruises, for instance.

Ammonium is, not surprisingly, the most difficult nutrient to preserve for long periods in the same conditions as the other nutrients. Following Ota's (2010) data which showed that vacuum-sealed aluminium-plastic bags prevent water vapour loss, such bags were tentatively used to wrap ammonium samples (but not under vacuum), expecting they were not permeable to ammonium present in laboratory air. After four ILE using these bags, no improvement could be noted in ammonium contamination. Within a 1-2 month delay allocated for sample analysis, pasteurized samples are convenient for ammonium interlaboratory exercises. Unfortunately, pasteurization is not satisfactory for the preservation of field seawater samples for ammonium since hydrolysis of the matrix produces measurable amounts of that nutrient. 


\section{Acknowledgements}

We are very grateful to Agnès Youénou for her helpful collaboration during the preparations of the inter-laboratory exercises. We also thank two anonymous reviewers for their constructive comments.

\section{References}

Aminot $A$, Kérouel $R$. Autoclaved sea water as a reference material for the determination of nitrate and phosphate in sea water. Anal Chim Acta1991; 248:277-83.

Aminot A, Kérouel R. Reference material for nutrients in seawater: stability of nitrate, nitrite, ammonia and phosphate in autoclaved samples. Mar Chem 1995; 49:221-32.

Aminot A, Kérouel R. Stability and preservation of primary calibration solutions of nutrients. Mar Chem 1996; 52:173-81.

Aminot A, Kérouel R. Reference material for nutrients for the QUASIMEME laboratory performance studies 1993-1996. Mar Pol Bull 1997a; 35(1-6):78-83.

Aminot A, Kérouel R. Assessment of heat treatment for nutrient preservation in seawater samples. Anal Chim Acta 1997b; 351:299-309.

Aminot A, Kérouel R. Pasteurization as an alternative method for preservation of nitrate and nitrite in seawater samples. Mar Chem 1998; 61:203-8.

Aminot A, Kérouel R, Coverly SC. Nutrients in seawater using segmented flow analysis. In: Wurl O editors. Practical guidelines for the analysis of seawater. Boca Raton, USA: CRC Press; 2009. p. 143-78.

Aminot A, Kirkwood DS. Report on the results of the fifth ICES intercomparison exercise for nutrients in sea water. ICES Cooperative Research Report 1995; 213:1-79.

Aoyama M, Becker S, Dai M, Daimon H, Gordon LI, Kasai H, Kerouel R, Kress N, Masten D, Murata A, Nagai N, Ogawa H, Ota H, Saito H, Saito K, Shimizu T, Takano H, Tsuda A, Yokouchi K, Youenou A. Recent comparability of Oceanographic Nutrients Data: Results of a 2003 Intercomparison Exercise using Reference Materials. Analytical Science 2007; 23:1151-4.

Aoyama M, Barwell-Clarke J, Becker S, Blum M, Braga ES, Coverly SC, Czobik E, Dahllof I, Dai MH, Donnell GO, Engelke C, Gong GC, Gi-Hoon Hong, Hydes DJ, Jin MM, Kasai H, Kerouel R, Kiyomono Y, Knockaert M, Kress N, Krogslund KA, Kumagai M, Leterme S, Yarong Li, Masuda S, Miyao T, Moutin T, Murata A, Nagai N, Nausch G, Ngirchechol MK, Nybakk A, Ogawa H, van Ooijen J, Ota H, Pan JM, Payne C, Pierre-Duplessix O, PujoPay M, Raabe T, Saito K, Sato K, Schmidt C, Schuett M, Shammon TM, Sun J, Tanhua T, White L, Woodward EMS, Worsfold P, Yeats P, Yoshimura T, Youenou A, Zhang JZ. 2006 Inter-laboratory Comparison Study for Reference Material for Nutrients in Seawater. Technical Reports of the Meteorological Research Institute (Tsukuba, Japan) 2008; 58:1104.

Bakker K., van Ooijen J., van Weerlee E., Epping E. A comparison of silicate standards in nutrients analyses. In: Aoyama M, Dickson AG, Hydes DJ, Murata A, Oh JR, Roose P, Woodward EMS, editors. Comparability of nutrients in the world's ocean. Tsukuba Japan: Mother Tank; 2010, p. 127-139.

Clancy V, Willie S. Preparation and certification of a reference material for the determination of nutrients in seawater. Anal Bioanal Chem 2004; 378:1239-42.

Hydes DJ, Aoyama M, Aminot A, Bakker K, Becker S, Coverly S, Daniel A, Dickson AG, Grosso O, Kerouel R, van Ooijen J, Sato K, Tanhua T, Woodward EMS, Zhang JZ. Recommendations for the Determination of Nutrients in Seawater to High Levels of Precision and Inter-Comparability using Continuous Flow Analysers. In: Hood EM, Sabine CL, Sloyan BM, editors. The GO-SHIP Repeat Hydrography Manual: A Collection of 
Expert Reports and Guidelines. IOCCP Report 2010; 14 (ICPO Publication Series Number 134). Available online at: http://www.go-ship.org/HydroMan.html.

ISO 13528:2005. Statistical methods for use in proficiency testing by interlaboratory comparisons.

Joyce T, Corry C. Requirements for WOCE hydrographic programmed data reporting. WHPO Publication 90-1 rev. 2, WOCE Report No. 67/91. 1994.

Kirkwood DS, Aminot A, Perttilä M. ICES Report on the results of the fourth intercomparison exercise for nutrients in sea water. ICES Coop. Res. Rep. 1991; 174:183.

QUASIMEME. Laboratory Performance Studies AQ-2 Nutrients in estuarine water and low salinity open water. Round 62 - Exercise 895. July 2010 to October 2010. 2010, Report Issue 1: 17112010, $38 \mathrm{p}$.

Ota $\mathrm{H}$, Mitsuda $\mathrm{H}$, Kimura M, Kitao $\mathrm{T}$. Reference materials for nutrients in seawater: their development and present homogeneity and stability. In: Aoyama M, Dickson AG, Hydes DJ, Murata A, Oh JR, Roose P, Woodward EMS, editors. Comparability of nutrients in the world's ocean. Tsukuba Japan: Mother Tank; 2010, p. 11-30.

\section{Tables}

Table 1. Repeatability of nutrient determinations: pooled data from 2006 to 2010 . Values in micromole per litre.

\begin{tabular}{lcccccc} 
& \multicolumn{2}{c}{ Low level } & & \multicolumn{3}{c}{ High level } \\
\cline { 2 - 3 } \cline { 5 - 7 } Nutrient & range & sd & & range & sd & $\%$ \\
\hline Ammonium & $0.05-0.7$ & 0.004 & & $2.1-4.5$ & 0.007 & 0.19 \\
Nitrite & $0.1-0.4$ & 0.0018 & & $0.5-1.5$ & 0.0023 & 0.26 \\
Nitrate & $1-5$ & 0.008 & & $15-35$ & 0.037 & 0.16 \\
Phosphate & $0.1-0.5$ & 0.004 & & $1.2-2.9$ & 0.005 & 0.26 \\
Silicate & $1-4$ & 0.015 & & $12-30$ & 0.030 & 0.15
\end{tabular}


Table 2. Characteristics of LNSW in the nutrient Inter-laboratory exercises and nutrient measured in the samples just after pasteurization. Salinity on practical salinity scale; nutrients in micromole per litre.

\begin{tabular}{|c|c|c|c|c|c|c|c|c|}
\hline \multirow{2}{*}{ Determinand } & \multirow{2}{*}{ Sample } & \multicolumn{7}{|c|}{ Inter-laboratory exercises (year-rank) } \\
\hline & & 2006 & 2007 & 2008 & 2009-1 & $2009-2$ & $2010-1$ & $2010-2$ \\
\hline Salinity & LNSW & 35.29 & 35.39 & 34.93 & 34.70 & 34.70 & $34.85^{1}$ & $34.85^{1}$ \\
\hline $\mathrm{pH}$ & LNSW & 8.21 & 8.18 & 8.09 & 8.00 & 8.22 & 8.06 & 8.21 \\
\hline \multirow[t]{3}{*}{ Ammonium } & LNSW & $\leq 0.01$ & $\leq 0.01$ & $\leq 0.01$ & $\leq 0.01$ & $\leq 0.01$ & 0.04 & 0.02 \\
\hline & Low level & 0.05 & 0.52 & 0.43 & 0.68 & 0.47 & 0.56 & 0.32 \\
\hline & High level & 4.41 & 2.08 & 3.63 & 4.48 & 3.05 & 3.91 & 2.44 \\
\hline \multirow[t]{3}{*}{ Nitrite } & LNSW & $\leq 0.01$ & $\leq 0.01$ & $\leq 0.01$ & $\leq 0.01$ & $\leq 0.01$ & $\leq 0.01$ & $\leq 0.01$ \\
\hline & Low level & 0.104 & 0.271 & 0.180 & 0.373 & 0.277 & 0.249 & 0.160 \\
\hline & High level & 0.469 & 0.955 & 0.764 & 1.217 & 1.026 & 1.374 & 0.731 \\
\hline \multirow[t]{3}{*}{ Nitrate } & LNSW & $<0.1$ & $<0.1$ & $<0.1$ & $<0.1$ & $<0.1$ & $<0.05$ & $<0.05$ \\
\hline & Low level & 1.01 & 2.19 & 1.62 & 3.13 & 1.68 & 2.85 & 4.43 \\
\hline & High level & 20.92 & 14.76 & 25.36 & 18.45 & 28.70 & 20.61 & 34.52 \\
\hline \multirow[t]{3}{*}{ Phosphate } & LNSW & $\leq 0.01$ & $\leq 0.01$ & $\leq 0.01$ & $\leq 0.01$ & $\leq 0.01$ & $\leq 0.01$ & $\leq 0.01$ \\
\hline & Low level & 0.104 & 0.517 & 0.225 & 0.285 & 0.412 & 0.241 & 0.173 \\
\hline & High level & 1.604 & 1.538 & 2.253 & 1.226 & 1.787 & 1.382 & 2.922 \\
\hline \multirow[t]{3}{*}{ Silicate } & LNSW & 2.0 & 0.5 & 0.4 & 0.4 & 4.1 & 1.15 & 4.8 \\
\hline & Low level & 2.04 & 2.60 & 1.17 & 1.15 & 4.04 & 1.38 & $2.71^{2}$ \\
\hline & High level & 17.13 & 12.64 & 24.60 & 24.36 & 28.62 & 14.89 & 22.62 \\
\hline
\end{tabular}


Table 3. Effect of pasteurization on the nutrient concentrations ( $\mu \mathrm{mol} / \mathrm{L})$.

\begin{tabular}{|c|c|c|c|c|c|}
\hline \multirow{3}{*}{ Nutrient } & \multirow{3}{*}{ Sample } & \multicolumn{4}{|c|}{ Effect of pasteurization } \\
\hline & & \multicolumn{2}{|c|}{ By level } & \multicolumn{2}{|c|}{ Overall } \\
\hline & & mean & $\mathrm{s}$ & mean & $\mathrm{s}$ \\
\hline \multirow[t]{2}{*}{ Ammonium } & Low level & +0.07 & 0.03 & \multirow{2}{*}{+0.07} & \multirow{2}{*}{0.03} \\
\hline & High level & +0.06 & 0.03 & & \\
\hline \multirow[t]{2}{*}{ Nitrite } & Low level & +0.001 & 0.002 & \multirow{2}{*}{0.000} & \multirow[b]{2}{*}{0.002} \\
\hline & High level & -0.001 & 0.001 & & \\
\hline \multirow[t]{2}{*}{ Nitrate } & Low level & 0.00 & 0.01 & \multirow{2}{*}{+0.01} & \multirow{2}{*}{0.03} \\
\hline & High level & +0.02 & 0.04 & & \\
\hline \multirow[t]{2}{*}{ Phosphate } & Low level & +0.001 & 0.003 & \multirow{2}{*}{+0.004} & \multirow{2}{*}{0.006} \\
\hline & High level & +0.007 & 0.007 & & \\
\hline \multirow[t]{2}{*}{ Silicate } & Low level & -0.02 & 0.03 & \multirow{2}{*}{-0.01} & \multirow{2}{*}{0.05} \\
\hline & High level & -0.01 & 0.06 & & \\
\hline
\end{tabular}

Table 4. Sample homogeneity at the various controls as the maximum standard deviations $(\mu \mathrm{mol} / \mathrm{L})$ of the seven ILE (2006-2010).

\begin{tabular}{lccccccc}
\multirow{2}{*}{ Nutrient } & \multicolumn{3}{c}{ Low level } & & \multicolumn{3}{c}{ High level } \\
\cline { 2 - 4 } \cline { 7 - 8 } & $<10$ days & 3-4 months & $8-40$ months & $<10$ days & 3-4 months & $8-40$ months \\
\hline Ammonium & 0.020 & 0.016 & 0.016 & & 0.018 & 0.021 & 0.019 \\
Nitrite & 0.001 & 0.001 & 0.002 & & 0.005 & 0.005 & 0.004 \\
Nitrate & 0.010 & 0.006 & 0.006 & & 0.021 & 0.020 & 0.010 \\
Phosphate & 0.001 & 0.006 & 0.006 & & 0.001 & 0.009 & 0.005 \\
Silicate & 0.007 & 0.006 & 0.015 & & 0.024 & 0.044 & 0.044
\end{tabular}

Table 5. Stability evaluation of the nutrients in the pasteurized samples over the 40-month period.

\begin{tabular}{|c|c|c|c|c|c|}
\hline \multirow{3}{*}{ Nutrient } & \multirow{2}{*}{\multicolumn{2}{|c|}{ Spearman correlation }} & \multicolumn{3}{|c|}{ Degree of stability } \\
\hline & & & \multirow{2}{*}{$\begin{array}{c}\text { Low level } \\
\mu \mathrm{mol} / \mathrm{L}\end{array}$} & \multicolumn{2}{|c|}{ High level } \\
\hline & $\alpha=0.05$ & p-value & & $\mu \mathrm{mol} / \mathrm{L}$ & $\%$ \\
\hline Ammonium & 0.893 & $<0.0001$ & 0.05 & 0.05 & 1.5 \\
\hline Nitrite & 0.037 & 0.831 & 0.002 & 0.004 & 0.4 \\
\hline Nitrate & -0.318 & 0.060 & 0.02 & 0.09 & 0.4 \\
\hline Phosphate & -0.399 & 0.016 & 0.004 & 0.010 & 0.5 \\
\hline Silicate & -0.299 & 0.077 & 0.05 & 0.07 & 0.3 \\
\hline
\end{tabular}




\section{Figures}

Figure 1. Stability controls on pasteurized samples. Concentration variation from initial value in absolute value for the low level (left axis: $\square$ ) and in percent for the high level (right axis: $\mathbf{}$ ). Each point is the average of homogeneity data.
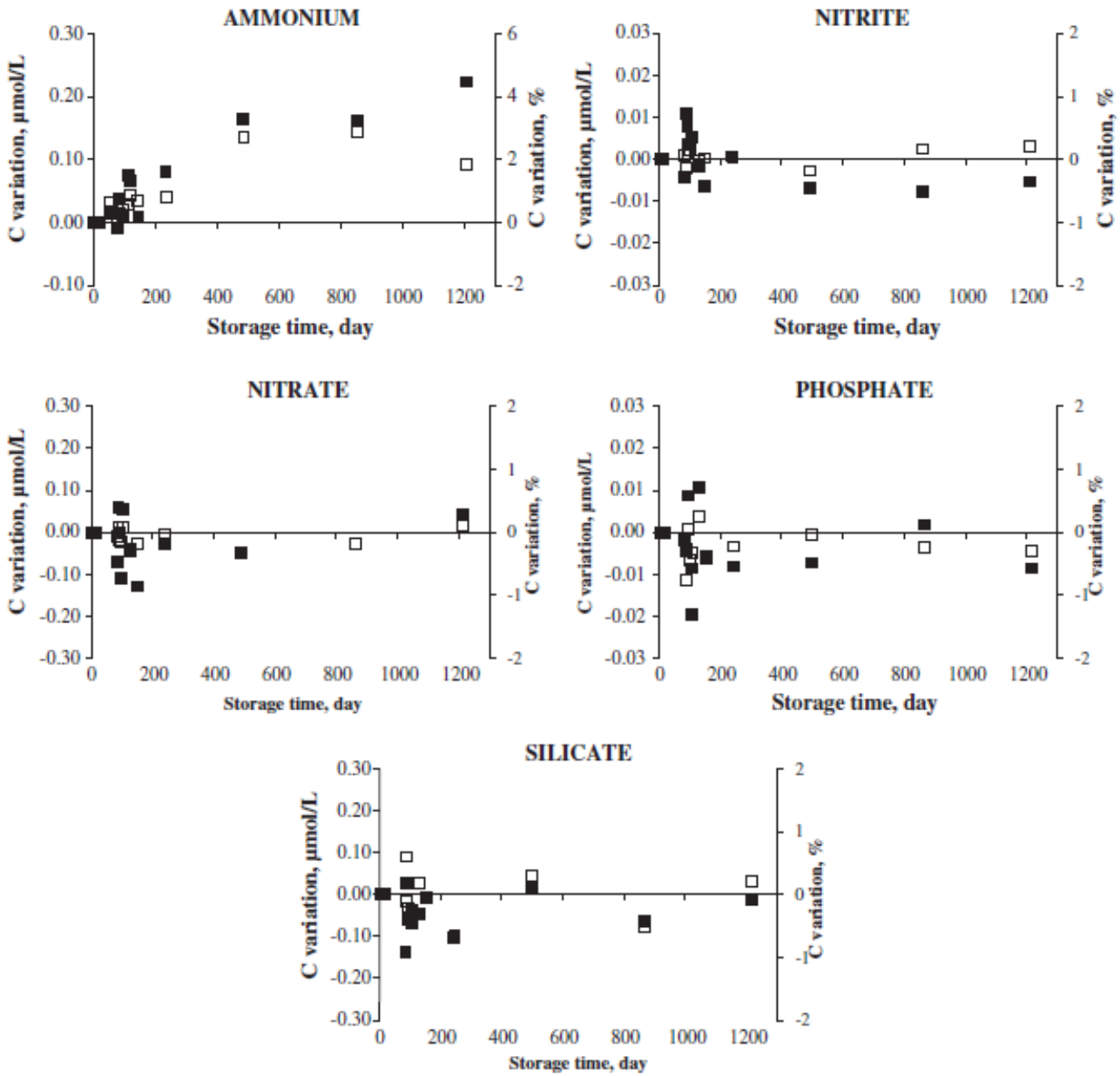
Figure 2. Comparison of participant data with ours for the 14 lots of the 7 ILE. The Quasimeme Programme allocated ranges for total error are drawn.
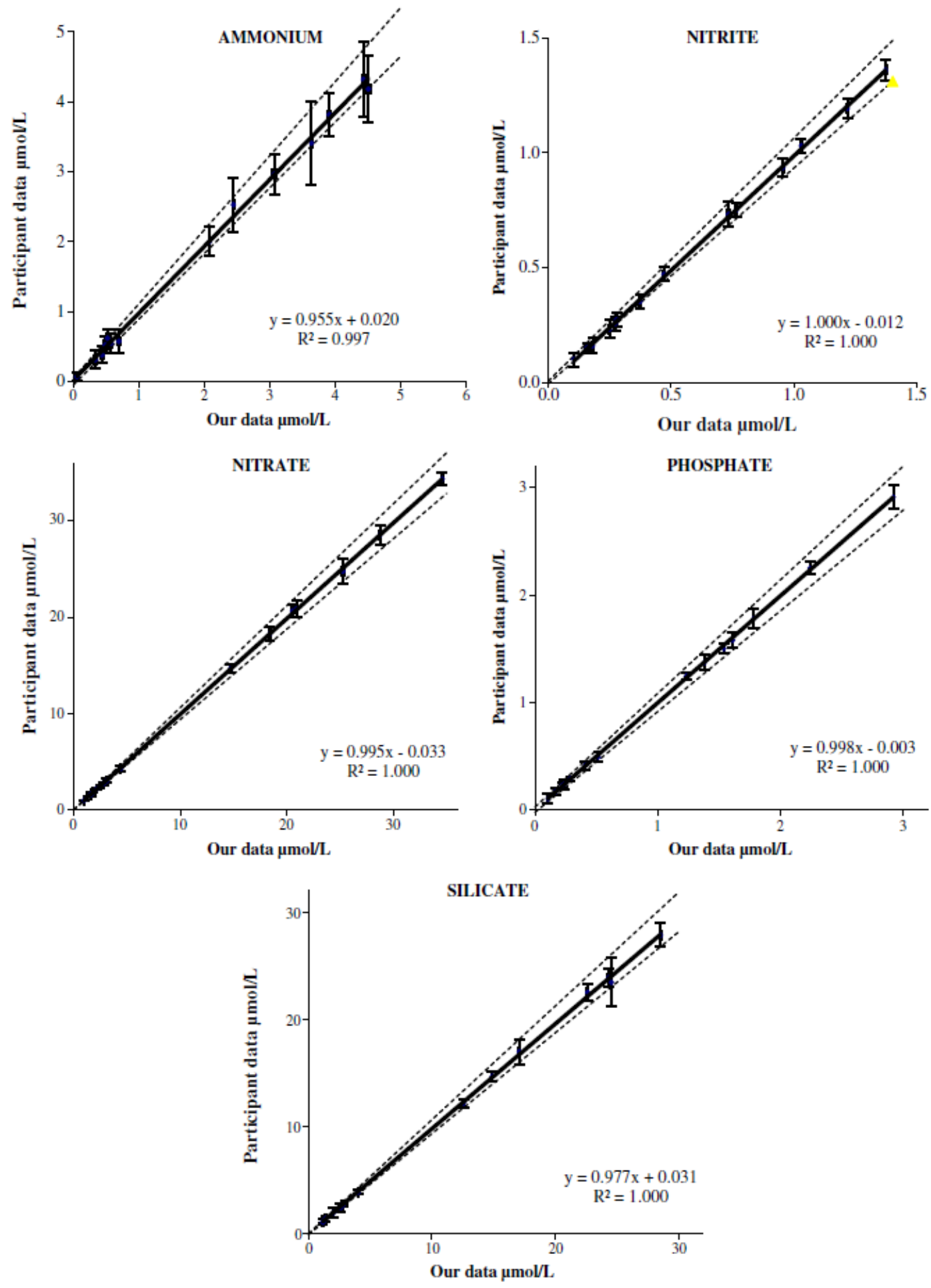